\title{
A influência da frenologia no Instituto Histórico de Paris: raça e história durante a Monarquia de Julho (1830-1848)
}

Cristian Cláudio Quinteiro Macedo

\section{Resumo}

A historiografia aponta a segunda metade do século XIX como período definidor do racismo científico. Todavia, os primeiros cinquenta anos dos mil e oitocentos produzem diversas disciplinas responsáveis pela gestação do ideário racial que eclodiria mais tarde. A frenologia é uma delas. O presente artigo aponta alguns elementos que demarcam a influência desta "ciência" durante o período conhecido como Monarquia de Julho em uma das principais instituições francesas que se ocupava com a história: o Instituto Histórico de Paris. Palavras-chave: Frenologia - Racismo - Instituto Histórico de Paris. 


\section{Introdução}

Quinze anos haviam se passado desde a Restauração. A França, principalmente Paris, não se ajustara à tentativa de retorno ao Antigo Regime, uma realidade soterrada pela Revolução Francesa. Após Carlos X instituir leis que desfaziam a câmara recém-eleita e impediam a liberdade de imprensa, o povo vai às ruas e, nas três gloriosas jornadas de julho de I830, retira o monarca do poder, elevando ao trono Louis Philippe d'Orléans (I773-I850).

No período conhecido como Monarquia de Julho se percebe um aumento do número dos instituts savants, sociedades voltadas às ciências, às artes, à filosofia, à higiene etc., frequentadas por intelectuais profissionais ou diletantes. Um dos mais significativos é o Instituto Histórico de Paris, onde historiadores, médicos, arquitetos, filósofos, poetas, naturalistas, advogados, educadores se reuniam em classes de estudo e pesquisa voltados ao saber histórico. Ao lermos as publicações sob responsabilidade deste Instituto, percebemos que a visão de história que cultivava era marcada pela noção de "utilidade social", em que o tema "raça" foi constantemente debatido.

A frenologia, ciência organizada por Franz Joseph Gall (I758-I828) e seu discípulo Johann Gaspar Spurzheim (I776-I832), ganha importância na França na primeira metade do século XIX e é citada diretamente, ou tem seus princípios defendidos, em muitas das discussões que ocorrem no Instituto Histórico.

O presente trabalho visa pontuar alguns elementos que evidenciam a participação e a influência da frenologia nas questões discutidas pelos membros do Instituto Histórico durante a Monarquia de Julho, entre as quais destacaremos a noção de raça.

\section{As ideias de raça}

A fim de entender as noções de raça que marcavam a sociedade francesa durante a Monarquia de Julho, vale a pena lançar mão da cronologia proposta por Andreas Hofbauer, a partir do que é tratado como "biologização das diferenças" em sua obra Uma história de branqueamento ou o negro em questão.

Ao pensar nas "lentas transformações na interpretação do mundo e do 'outro'" por parte dos europeus e norte-americanos no final do século XVIII, Hofbauer aponta três grandes tendências: (a) "a crença na razão" (b) "a crença na força da natureza, pensada cada vez mais como 'reino da biologia'” e (c) "a crença no progresso". O autor enfatiza essas crenças como "novas referências 
para pensar o mundo", servindo como critérios "para avaliar diferenças humanas" (HOFBAUER, 2006, p. II8).

A partir dos "novos valores de uma burguesia em ascensão", o autor marca oposições como a da "ordem divina inalterável" contra "ideais secularizados, tais como empreendimento, ascensão e desenvolvimento". Hofbauer também afirma que o que mais movia o homem da virada do século XVIII para o XIX era "o anseio de obter o sucesso individual ainda nessa terra" e nem tanto o "desejo de um dia atingir o paraíso" (Idem).

Com a perda gradual do poder explicativo dos dogmas religiosos, a elaboração de "métodos para classificar e categorizar o mundo natural" ganhava espaço. O homem, sendo parte da natureza, começa a ser estudado sob a ótica das técnicas utilizadas nas ciências naturais. Nascia a antropometria. Nesse contexto, surgem diversas disciplinas que cultivavam ideias de relação entre aspectos físicos e traços morais. A frenologia de Gall e a fisiognomonia de Johann Kasper de Lavater (I74I-I80I) são frutos desse espírito. Segundo Hofbauer "as distinções entre raças superiores e inferiores elaboradas referiam-se cada vez menos a uma ordem natural divinizada e cada vez mais a um ideário biológico e/ou a escalas de evolução”. O autor destaca, porém, que os primeiros cientistas dedicados à antropometria, entre eles Pieter Camper (I722-I789) e Johann Friedrich Blumenbach (I752-I840), "não descartavam totalmente a possibilidade de transformação de cor de uma raça", isto é, não essencializavam a ideia de raça (Idem, p. II9-I2I).

Blumenbach, criador do termo "raça caucasiana", entende essa "variedade" racial como o tipo "primordial da humanidade - cujas formas cranianas considera as mais bonitas do mundo”. As quatro variações dessa raça (mongólicos, etíopes, americanos e malaios) seriam suas degenerações, aproximando Blumenbach suas ideias às de Georges-Louis Leclerc de Buffon (I707-I788) que acreditava que a raça caucásica era a original e as demais, diferenciações ou degenerações dadas a partir do clima. Além disso, não delimita uma fronteira clara entre as raças humanas, abrindo mão de uma classificação que apresentasse diferenças substanciais entre os seres humanos. Após I795, apresenta a ideia de que os corpos humanos teriam "forças geradoras" que, a partir de "influências externas adequadas", revelariam características hereditárias, mudando assim sua concepção racial ligada ao clima (Idem, p. I2I).

Immanuel Kant (I724-I804), que segundo Blumenbach foi o primeiro a diferenciar claramente "variedades" e "raças", tratou da questão racial em dois textos: Das diversidades humanas, de I775, e Definição do conceito de raça humana, de I785. Seu ponto inicial é uma crítica que faz às ideias de Buffon em relação à 
importância do clima na explicação da variedade das raças. O filósofo alemão propõe que nos corpos orgânicos existiam "keime", germes que seriam fundamentais na ocorrência de determinados desenvolvimentos orgânicos. Fatores externos seriam importantes na medida em que possibilitariam a ação desses "germes". Dessa forma, o clima seria uma espécie de catalisador do processo e não seu fundamento. Dentro disso, não existiriam possibilidades de reverter as características raciais: o negro não se tornaria branco ou vice-versa. Ao definir o que seria raça, Kant dá primazia aos aspectos hereditários, assim, a cor da pele é um dos traços fundamentais na classificação de seres humanos. Ao propor uma "filosofia da história da humanidade", crê no progresso do gênero humano, todavia entende que somente a raça branca é passível de alcançar a perfeição civilizatória. Pensador que sustenta a primazia da razão, vê nos costumes não europeus indícios de baixa racionalidade, logo de poucas chances de ascender ao cume da civilização, em especial a raça negra cuja diferença frente à branca lhe parece imensa (Idem, p. 122-I24).

Hofbauer afirma que, no início do século XIX, existiam muitos métodos e critérios delimitadores de raças humanas, todavia, com o tempo, os métodos antropométricos seriam cada vez mais utilizados para defini-las. O uso do termo "raça" pelos europeus se tornou corrente e, "mesmo tendo sido raramente definido com precisão pelos cientistas da época, transformar-se-ia na noção paradigmática usada para conceituar grupos humanos" (Idem, p. I24).

\section{O Otelo brasileiro de Balzac}

Publicado durante o ano de I846, o folhetim A prima Bete, de Honoré de Balzac (I799-I850), traz o único personagem brasileiro presente nas centenas de páginas de A comédia humana do famoso romancista francês. Seu nome: barão Henrique Montès de Montejanos, descrito pelo romancista da seguinte forma:

dotado, pelo clima equatorial, do físico e da cor que todos julgamos características do Otelo do teatro [...]. A força muscular que o seu corpo bem talhado revelava $[\ldots]$. A fronte, saliente como a de um sátiro, sinal de teimosia na paixão, era ornamentada com uma cabeleira cor de azeviche, densa como uma floresta virgem, sob a qual cintilavam dois olhos claros, fulvos, o que fazia crer que a mãe do barão, quando grávida, teve medo de algum jaguar (BALZAC, I999, p. I75-I56). 
Ao longo do folhetim, o brasileiro é chamado de "barão moreno", "belo jaguar fugido das matas virgens do Brasil", "selvagem" e "cabeça de tigre”. Além disso, os brasileiros são tidos como "uns cabeçudos que fazem questão de ser empalados pelo coração". Neste caso, o autor usa o brasileiro Montejanos e sua brutalidade selvagem "domada" por sua amante, Valéria, como um exemplo de fera controlada pela força da paixão feminina. Ao mesmo tempo em que é feroz, é ingênuo (Idem, p. 372).

O fundo do pensamento balzaquiano que vai produzir esse personagem certamente nos escapa, todavia, podemos mapear dois aspectos da descrição do fictício brasileiro cujas "fontes" estavam bem próximas a Balzac.

O fator "degenerativo" da raça portuguesa no Brasil havia sido analisado nas páginas de uma das revistas que traziam os folhetins de Balzac, a Revue des Deux Mondes. O estudo intitulado Le Brésil en 1844 foi publicado em duas partes ${ }^{\mathrm{I}}$, trazendo as concepções raciais em voga no período. Nele, L. de Chavagnes, seu autor, afirma que o Brasil é habitado por membros da "race portugaise dégénérée", e isso seria um problema para que se alcançasse o que o povo brasileiro, em especial os habitantes do Rio de Janeiro, desejava: que o Brasil fosse "le point central de la civilisation dans l'Amérique du Sud", e um dia "rivaliser avec les États-Unis et servir de modéle à toutes les populations de l'Amérique méridionale". A feiúra, a ignorância e a vaidade da população foram destacadas pelo autor. Segundo ele, no Rio de Janeiro, apenas "quatre ou cinq femmes qu'on pourrait citer pour leur beauté; toutes les autres n'ont ni attreit ni séduction"; elas lhe causavam "une répulsion invincible". Os homens não eram mais agradáveis que as mulheres, em função da "l'ignorance et l'amour propre" que traziam. Nesse espírito, Chavagnes faz um balanço racial da população brasileira, seguida de uma análise:

La population du Brésil est évaluée approximativement à cinq mllions. Ony distingue plusieurs races: $1^{\circ}$ les Portugais d'Europe naturalisée Brésiliens; $2^{\circ}$ les Portugais créoles nés dans le pays, ou Brésiliens proprement dits; $3^{\circ}$ les métis de blancs et de nègres, ou mulâtres; $4^{\circ}$ les métis de blancs et d'Indiens, ou cabres; $5^{\circ}$ les nègres d'Afrique; 6을 Indiens, partagés en diverses peuplades (CHAVAGNES, I842, p. 92).

I Le Brésil en 1844: Sa situation morale, politique, commerciale et finnancière. La société brésilienne (p. 66-Io6) e Le Brésil en 1844: Intérieur du pays. Les villes maritimes. Avenir politique. Rapports du Brésil avec l'Europe (p. 849-909), por L. de Chavagnes. 
Para o autor "le phénomène le plus remarquable que présente la population brésilienne, ce sont les empiétemens de la race mulâtre, la seule qui, au Brésil, augmente chaque année". A causa seria "la corruption des Européens" somada à "immoralité de toutes les classes". A única raça pura seria a dos índios selvagens. Brancos, mulatos, negros e índios teriam "rapports avec la même femme". A partir do que o autor chama de "croisement général" entre brancos e brancas com as raças mestiças "naît une population que le teint naturellement olivâtre, les cheveux noirs et épais, doivent faire regarder comme mulâtre" (Idem, p. 92). Talvez o Montejanos de Balzac, da cor de Otelo², tivesse a pele oliva como os brasileiros do artigo, e fosse visto como mulato.

Todavia, para Chavagnes, os mulatos não eram de todo ruins. Quando procurou um guia para suas expedições, usou os serviços de um mulato, pois, para essa atividade, "les mulâtres sont particulièrement propres", pois eles são "moins apathiques, moins indolens que les nègres, ils comprennent et exécutent vos ordres sans que vons ayez besoin de les répéter". Além disso, "les nègres marchent à pied à côté de vos mulets, tandis qu'un bon camarada mulâtre est presque toujours montê" (Idem, p. 7I).

O outro aspecto da descrição balzaquiana do brasileiro Montejanos, e que podemos perceber principalmente nas comparações com animais, tanto físicas quanto psicológicas, é a influência que recebe da fisiognomonia e, em certo sentido, da frenologia (foco do presente estudo).

Em voga no final do século XVIII e início do século XIX, a "ciência do rosto" conhecida como fisiognomonia ${ }^{3}$, atribuída a Lavater, prometia um método para desvendar o caráter dos indivíduos a partir da sua fisionomia. Abraçada por muitos pensadores franceses, é no romancista Balzac que ela passa a ter um de seus principais vulgarizadores. Relata-nos um de seus mais completos biógrafos, Graham Robb, que

Balzac comprara um "esplêndido" exemplar da Arte de conhecer os homens pela fisionomia, de Lavater, e mandou encaderná-lo: parecia um dicionário do rosto humano. [...] a cor de um olho, a forma de um rosto, o traçado de um lábio assumem enorme importância científica ou artística (ROBB, I995, p. II5).

As faces descritas por Balzac, verdadeiras "máscaras” a serem decodificadas e a espelharem o caráter do indivíduo, aparecem em inúmeras páginas da sua

2 Anteriormente, Balzac, na fala de um personagem, fez a seguinte menção a Otelo: "non-seulement stupide, mais de mauvais goût. Un homme à moitié nègre est seul capable de se conduire ainsi" (BALZAC, I832, p. 74).

3 Sobre o apogeu da fisiognomonia ver HARTLEY, 2005. Sobre a fisiognomonia atualmente, consultar PÁDUA, [s. d.], p. 24-3I). 
A comédia humana. Mesmo diante de um retrato seu, feito por Achille Devéria (I800-I857), ele não abre mão de uma análise fisiognômica, apontando "a papada incipiente e a testa proeminente como certos indícios de tenacidade e de um intelecto poderoso", além do "nariz ligeiramente fendido na ponta" denotando "capacidade de farejar segredos como um sabujo" (Idem, p. I37).

Antes mesmo de seu enorme sucesso na França, a fisiognomonia, no contexto de sua língua de origem, se difundia entre os intelectuais. Desde o final do século XVIII

la comunitat mèdica de parla alemanya es mostrava interessada per la fisiognomonia i, en general, per qualsevol teoria que relacionés les característiques de la cara i el cap amb les disposicions innates dels individus.

No és d'estranyar, per tant, que les teories de Gall presentessin força connexions amb la fisiognomonia, sobretot amb la versió d'aquesta última que va difondre el metge i pastor evangelista Johann Kaspar Lavater. Malgrat que tant la frenologia com la fisiognomonia compartien els mètodes descriptius de la Història Natural, les diferenciava el caràcter analític i quantitatiu de la primera (MATEO, 2004 , p. IO).

Com a influência da fisiognomonia, mas com um caráter "analítico e quantitativo”, a frenologia surge a partir dos estudos de Franz Joseph Gall e de seu discípulo Johann Gaspar Spurzheim, cientistas de língua alemã que acabam por difundir suas ideias, o primeiro em língua francesa e o segundo para a comunidade de língua inglesa. Em linhas gerais, a ideia da disciplina frenológica era a de que a "conformação da caixa craniana, dependendo de seu tamanho e suas protuberâncias, designava diferentes aspectos da personalidade do indivíduo". Gall e Spurzheim "estabeleceram regiões anatômicas do crânio em relação a funções do cérebro responsáveis por virtudes e falhas do caráter" (ARREGUY, 20IO, p. I.269).

Em I843, outro retrato de Balzac é feito, mas agora por um artista conhecido por sua "arte frenológica", David d'Angers (I788-I856), deixando evidente uma testa alta em uma cabeça de grande proporção. Outro frenologista da relação de Balzac foi o médico da sua família, dr. Nacquart, tido como especialista nessa ciência de que o romancista também lança mão em suas obras (ROBB, I995, p. 55). Ele chega a escrever que "les belles recherches de Gall, le continuateur de Lavater [...] ont travaillé la pensée comme les opticiens ont travaillé la lumière" (BALZAG, I869, p. I2). Em verdade, podemos encontrar a fisiognomonia, a frenologia e tantas outras ideias que circulavam em Paris em A comédia humana de Balzac, combinadas, sem fronteiras bem definidas. Essa ausência de 
fronteiras entre as disciplinas parece comum, não somente na literatura do período da Monarquia de Julho, mas também em suas societés savants.

\section{A frenologia}

Gall chega à França em I807, com seu discípulo Spurzheim, trazendo sua nova ciência e uma bagagem intelectual influenciada por, entre outros, Johan Herman (I738-I800), naturalista alemão reconhecido por seus estudos de anatomia comparada dos animais. As semelhanças entre os cérebros dos símios e dos homens nas pesquisas de Herman marcaram o trabalho do pai da frenologia. $\mathrm{Na}$ capital da cultura e da ciência de então, as ideias frenológicas são absorvidas pelos naturalistas. Entre eles, Jean-Baptiste de Lamarck (I744-I829) e Étienne Geoffroy Saint-Hilaire (I779-I844). Até 22 de agosto de I828, data de sua morte, Gall permanecerá em Paris, cidade que o acolheu, chegando mesmo a se naturalizar francês em I8I9. Spurzheim, por outro lado, rompendo com o mestre em I8I3, passará a divulgar a frenologia na Inglaterra e nos Estados Unidos, sendo o responsável pelo grande sucesso da ciência no mundo anglo-saxão (GRAPIN, I973, p. IO-I3).

Estabelecendo-se na Grã-Bretanha, Spurzheim elabora, com o advogado George Combe, "una versión modificada del sistema de Gall para hacerlo más asequible a audiencias más amplias". Foi aí que se popularizou o termo frenologia (do termo grego para mente, phren, mais logos), que não foi usado por Gall que chamava sua ciência de Schädellehre ou organologia. Criado pelo médico Benjamin Rush (I746-I8I3) em I805, foi utilizado o termo frenologia em I8I8 por Thomas Foster (I794-I869) na sua obra Observations sur la phrénologie, que tratava da organologia de Gall. Combe e Spurzheim passaram a usar phrenology em suas palestras e textos. Além disso, os dois

añadieron un nuevo postulado que relacionaba el tamaño relativo de cada órgano del cerebro con su potencia; crearon una nomenclatura frenológica para designar las facultades mentales; postularon las aplicaciones terapéuticas, educativas y sociales de la nueva cienciay, en sus manos, la doctrina de Gall se convirtió en una auténtica ciencia del hombrey de la sociedad (LOPEZ \& HERNANDEZ, 2008, p. I26).

Spurzheim avançou Gall em número de faculdades sistematizadas a partir das localizações cerebrais. O mestre apresentou 27, enquanto o discípulo sugeriu 35. Também superou o mestre nas divulgações diretas de suas ideias: junto com George Combe, fundou 23 sociedades e vários periódicos frenológicos em língua inglesa (GRAPIN, I973, p. I2). 


\section{IV.I. Alguns conceitos da frenologia e a sua influência no pensamento oitocentista}

Os dois principais aspectos da teoria de Gall são a craneoscopia e a organopsicologia. A primeira foi a mais conhecida e, como ficou evidente mais tarde, a mais errada. A ideia de que hipertrofias de determinadas circunvoluções cerebrais causariam exteriormente desenvolvimentos aparentes na caixa craniana foi um equívoco defendido e utilizado por muitos sábios no século XIX. Isso, talvez, por que a promessa de, através de sinais exteriores, facilmente se chegar à natureza do indivíduo era fascinante: "según el Dr. Gall, palpando el relieve del craneo es posible apreciar la importancia relativa de los centros cerebrales, y por conseguiente, descubrir las 'cualidades'y el 'carácter' del sujeto examinado" (GRAPIN, I973, p. I6).

Quanto à organopsicologia, sua proposta era mapear o cérebro, que era entendido não como um órgão, mas como um conjunto de órgãos. Cada um deles seria a sede de determinada faculdade fundamental da alma ${ }^{4}$.

As teorias frenológicas exerceram influência em diversas áreas. $\mathrm{Na}$ antropologia, a partir dos estudos craneológicos, as medições "substituían a las impresiones intuitivas". Além disso, a frenologia vai ser fundamento para a antropologia criminal. Na etnografia, a figura de Pierre Marie Dumoutier (I797-I87I), frenólogo, foi essencial na expedição de Dumont d'Urville (I790-I842) à Oceania, onde a coleção etnológica do Musée de l'Homme é um de seus principais resultados. Extrapolando as esferas científicas, a influência da frenologia

es facilmente detectable en numerosas obras literarias (Balzac, Baudelaire, Flaubert, George Eliot, Edgar Poe, etcétera). Entre los discípulos de Gall hallamos a pintores como Gérard, a escultores como David d'Angers etc.

En fin, su aspecto positivista y su psicología no metafísica, suministraron notables elementos de base a quienes son considerados como los iniciadores de la sociología moderna: Auguste Comte y Herbert Spencer (GRAPIN, I973, p. I3).

4 1) Instinct de la génération; 2) amour de ses enfants; 3) douceur et affection; 4) propension à se défendre; 5) propension au meurtre; 6) goût des combats, ruse; 7) sentiment de la propriété; 8) sentiment de sa propre valeur; amour-propre; orgueil; 9) désir des honneurs et des richesses; ambition; 10) prudence; 11) mémoire des choses; 12) mémoire des lieux; 13) mémoire des personnes; 14) mémoire proprement dite (récitation, mémoire des mots;15) aptitude philosophique; 16) goût de la peinture; 17) goût de la musique; 18) aptitude pour les mathématiques; 19) aptitude pour les arts; 20) faculté analytique; raisonnement, comparaison etc.; 21) aptitude pour les sciences métaphysiques; 22) gaieté, enjouement, grâces de l’esprit; 23) aptitude pour la poésie; 24) bienveillance, bonté d'âme, compassion; 25) sens de la représentation et de l'imitation; 26) religion (SANTINI, [I8--], p. I4). 
Para muitos estudiosos da mente humana, a frenologia, assim como a fisiognomonia, faz parte de um longo processo que antecedeu a "descoberta do locus das emoções no cérebro". Durante muito tempo, a frenologia foi tida como uma pseudociência; todavia, atualmente, grande número de neurocientistas entende que o localizacionismo de Gall era fruto de "questões corretas com a tecnologia errada" (ARREGUY, 20IO, p. I.269).

\section{v. O Instituto Histórico de Paris e a frenologia}

Um dos tantos instituts savants da Monarquia de Julho foi o Instituto Histórico de Paris, fundado no final de I833, mas tendo sua primeira sessão oficial em I834. Com participação atuante de alguns brasileiros como Francisco de Sales Torres Homem (I8I2-I876) e Manoel de Araújo Porto-Alegre (I806-I879), serviu de inspiração para o Instituto Histórico e Geográfico Brasileiro, criado quatro anos depois em I838 (FARIA, I970). O Instituto Histórico de Paris foi espaço de amplas discussões não somente sobre a historiografia, mas também sobre as questões sociais de seu tempo. Com importantes membros ligados à frenologia, percebemos as constantes citações a Gall, além das reflexões referentes à raça, em suas sessões e congressos.

\section{V.I. O Instituto Histórico de Paris e a história útil}

Idealizada por Eugène Garay de Monglave (I796-I873), um amante da língua e da cultura brasileira, o Instituto foi presidido inicialmente por Joseph François Michaud (I767-I839), o famoso historiador das Cruzadas. Coube a Monglave o posto de secretário perpétuo, cargo que lhe foi entregue, mas do qual acabou abrindo mão em I846 quando deixou de frequentar a instituição (FARIA, I967).

Entre os sócios fundadores podemos destacar: Alphonse de Lamartine (I790-I869), deputado; Geoffroy Saint-Hilaire da Academia de Ciências; Jules Michelet (I798-I874) da Academia de Ciências Morais e Políticas; e André-Marie Ampère (I775-I836) da Academia de Ciências. Além de sócios franceses, o Instituto contava com membros correspondentes e também com protetores da nobreza. Com o objetivo estatutário de "estimular e propagar os estudos históricos na França e no estrangeiro" e pesquisar "tudo o que constitui a ciência histórica", foram organizadas seis classes de estudos e 
pesquisas $^{5}$. Para divulgar os resultados de seus trabalhos o Instituto Histórico mantinha uma revista (o Journal de L'Institut Historique), um evento anual reunindo os membros de todo o continente (o Congrès historique européen) e cursos públicos gratuitos (CARRARO, 2002).

Apesar de conter em seu estatuto a proposta da objetividade, sempre foi evidente nos debates e nos artigos produzidos pelos membros do Instituto que a história era uma disciplina que deveria ser útil ao progresso humano. Em verdade, ela era considerada como "condição de todo progresso". A história descobria as leis sociais, além de mostrar quais delas serviam ao aperfeiçoamento social. Nos congressos realizados pelo Instituto se conclamava seus membros a pensarem "apenas nos grandes interesses morais", entendendo-se a disciplina histórica como "portadora de verdade, moralidade e utilidade" e, para os membros do Instituto, a moral era o caminho para a "regeneração dos males sociais" (Idem, p. 59-83).

\section{v.II. Alguns membros do Instituto Histórico e da Sociedade Frenológica}

Três anos antes da primeira sessão do Instituto Histórico de Paris, surge a Sociedade Frenológica de Paris (I83I). Entre os seus membros fundadores estavam Casimir Anne Marie Broussais (I803-I847) e Jean-Baptiste Beunaiche de La Corbière (I80I-I879), médicos, tendo o primeiro o cargo de professor na Faculdade de Medicina de Paris. De seus quadros também fazia parte Hippolyte Léon Denizard Rivail (I804-I869), educador, filho de um magistrado de Bourg-an-Bresse, na França, foi discípulo de Johann Heinrich Pestalozzi (I746-I827), pedagogo suíço que centrava sua prática na educação moral. Estes três estudiosos da frenologia também faziam parte do Instituto Histórico de Paris, todos reunidos na $4^{\underline{a}}$ classe.

Broussais era filho de François-Joseph-Victor Broussais (I772-I838), médico, presidente durante muitos anos da Sociedade Frenológica e autor de livros de divulgação da ciência ${ }^{6}$. Casimir Brousais foi secretário-geral dessa

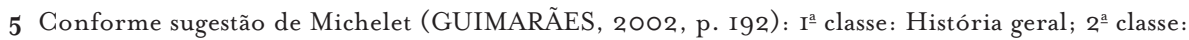
História das ciências sociais e filosóficas; $3^{\underline{a}}$ classe: História das línguas e das literaturas; $4^{\underline{a}}$ classe: História das ciências físicas e matemáticas; $5^{\text {a }}$ classe: História das belas-artes; 6ª classe: História da França. Posteriormente, a $4^{\underline{a}}$ classe se fundiu com a $2^{\underline{a}}$.

6 A última lição do Cours de Phrénologie de Brousais pai se intitula Application de la phrénologie à l'histoire (p. 789-847). 
sociedade e no Instituto Histórico de Paris foi vice-presidente. É dele o artigo que abre o primeiro número da revista do Instituto tratando, entre outras coisas, da utilidade da história e do quanto todas as disciplinas eram suas tributárias (BROUSSAIS, I834, p. I-3). Publicou um completo Atlas historique et bibliographique de la médecine. No Ier Congrès historique européen trata da questão: Rechercher dans l'histoire et dans les sciences l'origine de la phrenologie, que resultou em intenso debate entre os participantes (CONGRÈS, I836, p. 224-252). Na Sociedade Frenológica foi constante colaborador, assinando diversos estudos publicados no Journal de la Société Phrénologique de Paris.

La Corbière publicou vários estudos sobre medicina e frenologia. Um de seus mais conhecidos livros é o De l'influence que doit exercer la phrenologie sur les progres ulterieurs de la philosophie et de la morale, publicado em I853. Teve papel importante nos debates do Instituto, principalmente com a publicação do opúsculo Réponse aux objections faites a la phrénologie, au sein du congrès historique..., em que defende a condição científica da frenologia e sua relação com a história. Para o autor, a história já havia comprovado que o homem se transforma sob a "double influence des modificateurs moraux et hygiéniques", e essa transformação pode ocorrer sempre, durante sua vida. Dessa forma, ele convida os opositores à frenologia a visitarem escolas, hospitais e prisões, não só da Europa, mas também da América do Norte, para observarem os "chefs intellectuels" lançando mão do elemento frenológico amplamente difundido e inabalável como "la vérite sur laquelle elle repose" (LA CORBIÈRE, [s. d.], p. I5-I6). A história estava buscando identificar as leis sociais para produzir o progresso social. A frenologia, segundo seus adeptos, já o estava promovendo.

H. L. D. Rivail, dono de uma instituição educacional, poderia ser um desses "chefs intellectuels" referenciados por La Corbière. Foi presidente e depois vice-presidente da $4^{\underline{a}}$ classe do Instituto. No relato de uma das sessões informa-se que ele "se plaint du peu d'essais phrénologiques tentés sur les enfans", e que fazia um convite aos membros do Instituto Histórico: "visiter son institution et examiner ses élèves" (EXTRAITS, I835, p. 307). No campo teórico da frenologia, Rivail vai, no trabalho que apresenta na Sociedade Frenológica de Paris intitulado Sur les causes de dissidence entre les théologiens et les phrénologistes, definir três ramos da frenologia: "la facultologie", "l'organologie cérébrale" e "la cranioscopie"”.

7 Pour M. Rivail, la phrénologie se divise en trois branches: $1^{\circ}$ La facultologie, partie de la phrénologie qui traite de l'étude des facultés et de leurs combinaisons, c'est-à-dire des phénomènes de la vie intellectuelle et morale, abstraction faite de la cause première; 2 으organologie cérébrale, partie de la phrénologie qui traite des diverses sections du cerveau affectées à chaque faculté; $3^{\circ}$ La cranioscopie, partie qui traite de l'influence des organes cérébraux sur la forme du crâne, et des signes extérieures auxquels on peut apprécier le développement de ces organes. Par le mot de facultologie, substitué à celui de psychologie, la science se trouve 
Em I834, em sua instituição de ensino, H. L. D. Rivail apresenta suas ideias e ações no ensino da história ao discursar no dia da tradicional entrega de prêmios aos alunos. Neste discurso, o educador faz uma crítica à forma em que se ensinava esta disciplina ${ }^{8}$. Ao informar que "esta ciência é ensinada em toda parte por meio de livros apenas", contrapõe o sistema vigente ao dizer ter pensado em um modelo em que o estudo é feito "tanto para os olhos quanto para o espírito". Desenvolve um "quadro mnemônico" em que busca "apresentar os fatos da história de uma maneira sensível, por meio de desenhos", todavia afirma que não se preocupou somente em melhorar a visualização dos fatos históricos ensinados à época, normalmente reduzidos a narrações de feitos políticos, isto é, ao "conhecimento rigoroso de uma multidão de datas sem importância, de tratados, de batalhas, da filiação das casas dos soberanos, [que] forma o fundo deste estudo e o torna árido”. Em seu quadro, o educador privilegia uma história científica, aos moldes do Instituto, e apresenta "os costumes e usos que fazem conhecer os progressos das artes e das ciências, as origens". Para Rivail "os costumes (mœurs) aumentam ainda o interesse e a verdade [...], pois os costumes também fazem parte da história”, mas não abre mão (conforme o princípio frenológico das têtes superiores) de tomar por base "os homens célebres por que são eles que fazem a história e servem de centro para onde convergem os eventos de detalhe" (RIVAIL, I998, p. 89).

Seus escritos da segunda metade do século, ao tratar mais diretamente da raça negra, estão no contexto da sua obra espiritualista, sob pseudônimo, mas ainda com base na frenologia. No artigo Phrénologie spiritualiste et spirite: perfectibilité de la race nègre, de $\mathrm{I} 862$, ele defende que a raça negra pode progredir, mas com grandes limitações impostas pela sua biologia, já comprovadas pela frenologia. Segundo ele:

L'examen phrénologique des peuples peu intelligents constate la prédominance des facultés instinctives, et l'atrophie des organes de l'intelligence. Ce qui est exceptionnel chez les peuples avancés est la règle chez certaines races. Pourquoi cela? Est-ce une injuste préférence? Non, c'est de la sagesse. La nature est toujours prévoyante; elle ne fait rien d'inutile; or, ce serait une chose inutile de donner un instrument complet à qui n'a pas les moyens de s'en servir. Les Esprits sauvages sont des Esprits encore enfants, si l'on peut s'exprimer ainsi; chez eux, beaucoup de facultés sont encore latentes (KARDEC, I862, p. I03).

renfermée dans les véritables limites de ses attributions, et le mot phrenologie, qui comme qualification générale de la science ne sera plus confondu avec la cranioscopie, qui a un objet tout spécial, et qui n'en est véritablement qu'une division (SOCIETES, I843). 8 Antoine Prost, em seu Doze lições sobre a história, fala sobre a maneira como era feito o ensino de história nessa época "caricatural" (p. 23). 
A natureza não erra, por isso não dá a um espírito infantil "un instrument complet" (o corpo de um caucasiano), ela mesma demarca a limitação do negro e a superioridade do branco, e não somente física, pois esta advém da superioridade da alma. A natureza é justa ao dar corpos limitados a almas limitadas. Os negros "comme organisation physique, seront toujours les mêmes", e "comme Esprits, c'est sans doute une race inférieure, c'est-à-dire primitive", todavia, para eles, ainda existe uma esperança: podem ser educados. Apesar da sua limitação que os permite aprender "bien peu de chose", é possível neles "modifier certaines habitudes, certaines tendances, et c'est déjà un progrès" (Idem, p. IO4-IO5).

Fisicamente "la race nègre, en tant que race nègre, corporellement parlant, n'atteindra jamais le niveau des races caucasiques". Mesmo por que as "races sauvages" estão fadadas a extinção: “à mesure que les races civilisées s'étendent, les races sauvages diminuent, jusqu'à ce qu'elles disparaissent complétement, comme ont disparu les races des Caraïbes, des Guanches et autres" (Idem, p. I05).

Em outubro de I869, um artigo que Rivail havia preparado em fevereiro é publicado postumamente (ele morre em março daquele ano): Théorie de la beauté. A questão colocada no artigo era se a beleza física guardava relação com a superioridade da alma. A resposta, segundo o autor, é afirmativa. Para Rivail "la beauté réelle consiste dans la forme qui s'éloigne le plus de l'animalitê", animalidade esta que parece marcar a raça negra, logo, sua "fealdade":

Le nègre peut être beau pour le nègre, comme un chat est beau pour un chat; mais il n'est pas beau dans le sens absolu, parce que ses traits gros, ses lèvres épaisses accusent la matérialité des instincts; ils peuvent bien exprimer les passions violentes, mais ne sauraient se prêter aux nuances délicates du sentiment et aux modulations d'un esprit délié (KARDEC, I869, p. 23I).

Em um visível cruzamento de ideias fisiognômicas e frenológicas, o autor defende que o negro é feio por ter paixões violentas, por estar próximo à animalidade. Quanto aos europeus, ele afirma que podem, "sans fatuité", dizerem-se "plus beaux que les nègres et les hotentots" (Idem).

Retomando nosso período de estudo, a Monarquia de Julho, percebemos que, assim como Rivail, La Corbière e Broussais, o Instituto Histórico e a Sociedade Frenológica de Paris tiveram outros membros que faziam parte das duas instituições: François-Frédéric Poncelet (I790-I843), professor da Escola de Direito de Paris; Gabriel Andral (I797-I876), professor da Faculdade de Medicina de Paris; Philippe Joseph Henri Lemaire (I798-I880), escultor; Jean-Baptiste Mège (I787-I866), doutor em Medicina. Percorrer seus caminhos intelectuais talvez nos trouxesse apontamentos semelhantes aos que recolhemos de Rivail. 


\section{V.III. A raça nas seções do Instituto Histórico de Paris}

Nas páginas das publicações do Instituto Histórico, o termo raça aparece muitas vezes. Ao que parece, para seus membros, estudar a história de um povo era desvendar-lhe as matrizes raciais. Em alguns momentos, o termo raça aparece relacionado a determinadas linhagens de nobreza ("race heroique et chevaleresque", "race des rois francs"), em outros, surge com acepção próxima à que se consagrou principalmente na segunda metade do século XIX. Visando dar um olhar mais panorâmico, elencaremos abaixo algumas passagens em que a questão raça (na segunda acepção) apareceu, seja no Journal, seja nos anais do Congrès.

Em I834, é publicado um fragmento inédito da obra Un voyage pitoresque et historique au Brésil, de Jean-Baptiste Debret (I768-I848), presidente da $5^{\text {a }}$ classe do Instituto Histórico. Nele, a análise do mulato brasileiro é apresentada. Seria um "homme de couleur" que europeus e africanos engendraram em terras americanas, alguém com "l'organisation physique [...] plus robuste". Devido ao "sang africain, qui coule par moitié dans ses veines", o mulato tem um "tempérament en harmonie avec le climat" do Brasil, suportando "l'ardeur de ce soleil des tropiques". Para Debret, o mulato, em relação ao negro, tem "plus d'énergie" e, sobretudo, é "supérieur par son intelligence, qui le rapproche de la race blanche". Por outro lado, é "présomptueux, sensuel, irrascible et vindicatif". Vive em conflito com a raça branca que "le méprise à cause de sa couleur" e com a raça negra, que o "déteste à cause de sa supériorité" (DEBRET, I834, p. I72). Debret, em outros momentos, ao apresentar seus estudos, retomava a questão racial do Brasil, enquanto seus pupilos brasileiros (Torres Homem, Araújo Porto Alegre, Gonçalves de Magalhães), quando usavam da tribuna do Instituto, preferiam temas relacionados à literatura e às artes.

Em uma seção do ano de I835, Monglave, secretário perpétuo do Instituto Histórico, apresenta "détails peu connus sur le nègre Eustache" (EXTRAITS, I835, p. 307). Presente em diversas obras de frenologia, o caso de Eustache foi tomado como uma regra frenológica, mas uma exceção racial ${ }^{9}$.

Nascido no Haiti em I773, Eustache naturalmente evitava qualquer tipo de "conversacion obscena" e aproveitava toda oportunidade para "escuchar a respetables e intelijentes blancos". Em I79I, quando os escravos haitianos "cometieron toda clase de brutalidad", Eustache, em meio a "tanto crime itanta atrocidad", foi "impulsado por el mas vehemente deseo de hacer bien" e acabou salvando "a muchos blancos, entre ellos a su amo, a

9 Como a apresentação de Monglave não foi publicada na revista do Instituto Histórico, aqui usaremos o manual frenológico de Mariano Cubí i Soler (I808-I875) como base para uma "narrativa frenológica”, visando apresentar o caso. 
quien no abandonó jamas". Ao chegar à França, trabalhou sempre com "la mas férvida enerjia e incansable contancia, como criado e sirviente [...] olvidándo-se de sî". Outra atitude de Eustache digna de menção ocorreu antes da revolução haitiana, quando seu senhor perdia gradualmente a visão. Diante disso, Eustache "sentia amargamente no saber leer". Assim, resolveu "tomar lecciones secretamente de lectura a las cuatro de la madrugada, porque en su calidad de esclavo, no creia que podia pertenecerle otro tiempo que el que se le concedia para el sueño". Dessa forma, atendendo às necessidades de seu senhor, pôde ler para ele as obras de sua predileção. Em I832, o Instituto Nacional da França o premia com cinco mil francos, referentes ao primeiro premio de virtude (SOLER, I853, p. I73-I74).

Morre, em I836, "le nègre Eustache" e seu caso se torna modelar para os frenólogos, não diretamente pelos feitos morais (que seriam contrários ao que esperavam da parte de um homem negro), mas porque foram realizados por um negro que nasceu com um crânio semelhante ao dos caucasianos. Uma "exceção moral" no seio da raça negra só poderia ser explicada via frenologia.

Todavia, o autor que mais se destacou nos debates raciais e frenológicos do Instituto Histórico, sem dúvida, foi Alexandre Victor Courtet (I8I3-I867), membro da I ${ }^{a}$ classe e, posteriormente, secretário da Sociedade Etnológica de Paris. Conhecido como Courtet de l'Isle, pretendia desvendar a sociedade de forma análoga ao que Gall fez diante dos indivíduos:

De même que le docteur Gall s'écria un jour: Il y a dans le cerveau une multitude d'organes auxquels correspondent certaines prédispositions morales, et l'on peut, par la comparaison des signes extérieurs qui les représentent, découvrir de plus en plus les rapports élablis entre l'organisation cérébrale et le développement de l'intelligence; - S'il m'est permis de prendre un pareil ton de confiance, je m'écrierai à mon tour: Le genre humain peut être considéré comme le cerveau des règnes organisés; et les innombrables variétés dont il se compose sont autant d'organes spéciaux qui ont des fonctions distinctes, graduées el providentielles. Décrivons chacun de ces nouveaux organes, et cherchons en déterminer l'attribut social. - Telle est la seule pensée qui m'a préoccupé (COURTET, I835, p. 237).

Courtet de l'Isle, no ano de I835, apresentou dois trabalhos ao Instituto. Um chamado De l'influence des races humaines, sur la forme et le développement des sociétés (de onde foi retirada a citação acima), que seria a conclusão de uma obra que pretendia publicar, não antes, segundo ele, de expor os pensamentos fundamentais aos demais membros do Instituto para discussão. O outro trabalho que pretendia (conforme o título) Déterminer par l'histoire et par les sciences ce qu'on doit entendre par les mots genre, espèces et races, appliqués à l'homme, é lido na I $2^{\mathrm{a}}$ seção do Ier Congrès historique européen, e acaba abrindo o debate que dura alguns anos, nas páginas das publicações do Instituto, envolvendo as desigualdades raciais. 
Mas, neste debate, manteve-se aquela que seria uma verdade para seus membros: os negros estavam no último degrau racial. Mais tarde, Joseph Arthur de Gobineau (I808-I882), um dos maiores teóricos do racismo, usará muitos de seus argumentos, sem dar-lhe os devidos créditos (BANTON, I977, p. 53). Posteriormente, revisto por alguns autores, Courtet é apresentado como portador da ideia original de que "a história humana era determinada não só pelas lutas inter-raciais, 'fisicamente', mas também, de maneira mais íntima, pelas flutuantes misturas ou dosagens de sangues, e, portanto, 'quimicamente"” (POLIAKOV, I974, p. 212).

\section{vI. Considerações finais}

Intelectuais de destaque na Monarquia de Julho tinham no Instituto Histórico um meio de discutir e produzir história, dentro da perspectiva de utilidade social dessa disciplina: ela deveria relatar a verdade e produzir progresso. Como síntese desse espírito, temos seu vice-presidente, Phillippe Buchez (I796-I865) afirmando, na abertura do Ier Congrès historique européen, que a história "est la plus grave, la plus importante des sciences humaines [...] ses enseignemens s'adressent à toutes les spécialités, à toutes les circonstances, à tous les actes; (CONGRÈS, I836, p. IO). Nesse ambiente, médicos, operadores do direito, educadores e intelectuais de diversas áreas se reuniam para debater uma ciência que não somente procurava estudar o passado, mas também encontrar leis que produzissem o progresso social. Muitos desses estudos eram filtrados por princípios que cada um de seus membros cultivava. Entre esses princípios estavam os frenológicos, com sua perspectiva racial, perpassando a disciplina histórica.

Se, por um lado, a população parisiense travava contato com as ideias raciais via folhetins, como os de Balzac, por outro, talvez as absorvessem por intermédio de tantos médicos, juízes, artistas e educadores que, as debatendo em instituts savants, possivelmente as difundiam em suas atividades diárias junto à sociedade.

Ao percorrermos as páginas das publicações do Instituto Histórico de Paris, e um pouco do que foi produzido por alguns de seus membros, como H. L. D. Rivail, por exemplo, percebemos influentes membros que, não somente frequentavam a Sociedade Frenológica, mas inúmeros outros instituts. Eles formavam uma rede intelectual de grande influência social durante o período de governo de Louis Philippe e, possivelmente, o pensamento frenológico, associado ao histórico, por meio dessa rede, penetrou em variados ambientes intelectuais. Conhecer mais profundamente os caminhos dessa 
penetração poderá tornar cada vez mais claro o porquê do racismo científico da segunda metade do século XIX e sua adesão quase universal no período.

\section{Referências bibliográficas}

ARREGUY, Marília Etienne. A leitura das emoções e o comportamento violento mapeado no cérebro. Physis Revista de Saúde Coletiva. Rio de Janeiro: IMS-UERJ, no 20, 2010, p. I.267-I.292.

BALZAC, Honoré. A prima Bete. In: Idem. A comédia humana, vol. X. São Paulo: Globo, I990, p. 23-409.

Oeuvres complètes: La comédie humaine; Études de moeurs; Scènes de la vie privée, vol. I. Paris: Michel Lévy Frères éditeurs, I869.

Autre étude de femme. In: Oeuvres illustrées de Balzac. Paris: Marescq e J. Bry Ainé, I832, p. 7I-80.

BANTON, Michel. A ideia de raça. Lisboa: Edições 70, I977.

BROUSSAIS, Casimir. Introduction. Journal de l'Institut Historique, vol. I. Paris: P. Bandouin, I834, p. I-3.

BROUSSAIS, François-Joseph-Victor. Cours de Phrénologie. Paris: J. B. Bailliere, I836.

CARRARO, Elaine Cristina. O Instituto Histórico de Paris e a regeneração moral da sociedade. Dissertação de mestrado, Departamento de Sociologia do Instituto de Filosofia e Giências Humanas da UNICAMP, Campinas, 2002.

CONGRÈS HISTORIQUE EUROPEEN, reuni a Paris, au nom de l'Institut Historique. Paris: P. H. Krabe, I836.

COURTET, Alexandre Victor. De l'influence des races humaines, sur la forme et le développement des sociétés. Journal de l'Institut Historique, vol. 2. Paris: P. Baudouin, I835, p. 225-237.

CHAVAGNES, L. de. Le Brésil en I844. Revue des Deux Mondes. Paris: H. Fournier et Cie, I844, p. 66-Io6 e p. 849-909.

DEBRET, Jean-Baptiste. Moeurs e usages des brésiliens civilisés. Journal de l'Institut Historique, vol. I. Paris: P. Baudouix, I834, p. I70-I72.

EXTRAITS des procès-verbaux des assemblées générales et des séances de classes de l'Institut Historique. Journal de l'Institut Historique, vol. 2. Paris: P. Baudouin, I835, p. 304-308.

FARIA, Maria Alice de Oliveira. Brasileiros no Instituto Histórico de Paris. São Paulo: Conselho Estadual de Cultura, I970.

- Monglave e o Instituto Histórico de Paris. Revista do Instituto de Estudos Brasileiros. São Paulo, USP, nº 2, I967, p. 43-53. 
GRAPIN, Pierre. La antropología criminal. Barcelona: Oikos-tau, I973.

GUIMARÃES, Manoel Luís Salgado. Entre amadorismo e profissionalismo: as tensões da prática histórica no século XIX. Topoi. Rio de Janeiro, vol. 3, 2002, p. I84-200.

HARTLEY, Lucy. Physiognomy and the meaning of expression in nineteenth-century culture. Nova York: Cambridge University Press, 2005.

HOFBAUER, Andreas. Uma história de branqueamento ou o negro em questão. São Paulo: Unesp, 2006.

KARDEG, Allan. Phrénologie spiritualiste et spirite: Perfectibilité de la race nègre. Revue Spirite. Paris: Cosson et Cie, I862, p. 97-I05.

Théorie de la beauté. Revue Spirite. Paris: Caisse Générale, I869, p. 226-234.

LA GORBIÈRE, Jean-Baptiste Beunaiche de. Réponse aux objections faites a la phrénologie, au sein du Congrès Historique. Paris: imprimeirie de Pihan-Delaforest, [s. d.].

MATEO, David Nofre i. En els marges de la ciència? Frenologia i mesmerisme en una cultura industrial, Barcelona 1842-1845. Barcelona: Universitat Autònoma de Barcelona, 2004.

PÁDUA, Gláudia Maria França. Face do criminoso. Ciência e Vida Psique. São Paulo: Escala, no 65, [s. d.], p. 24-3I.

POLIAKOV, Léon. O mito Ariano. São Paulo: Perspectiva, I974.

PROST, Antoine. Doze lições sobre a história. Belo Horizonte: Autêntica, 2008.

RIVAIL, Hippolyte Léon Denizard. Discurso pronunciado na distribuição de prêmios do I4 de agosto de I834. In: Textos pedagógicos. São Paulo: Comenius, I998.

ROBB, Graham. Balzac: uma biografia. São Paulo: Companhia das Letras, I995.

SANTINI, Emmanuel-Napoléon. Traité de phrénologie. Paris: Le Bailly, [I8--].

SOCIETES savants: société phrénologique de Paris. In: Encyclographie des sciences médicales, tomo VII. Paris: Société Encyclographique, I843, p. I54.

SOLER, Mariano Cubí i. Lecciones de frenolojia. Barcelona: Castaños, I853.

Cristian Cláudio Quinteiro Macedo - Graduando em História pela Universidade Federal do Rio Grande do Sul.

cristian.macedo@ufrgs.br 